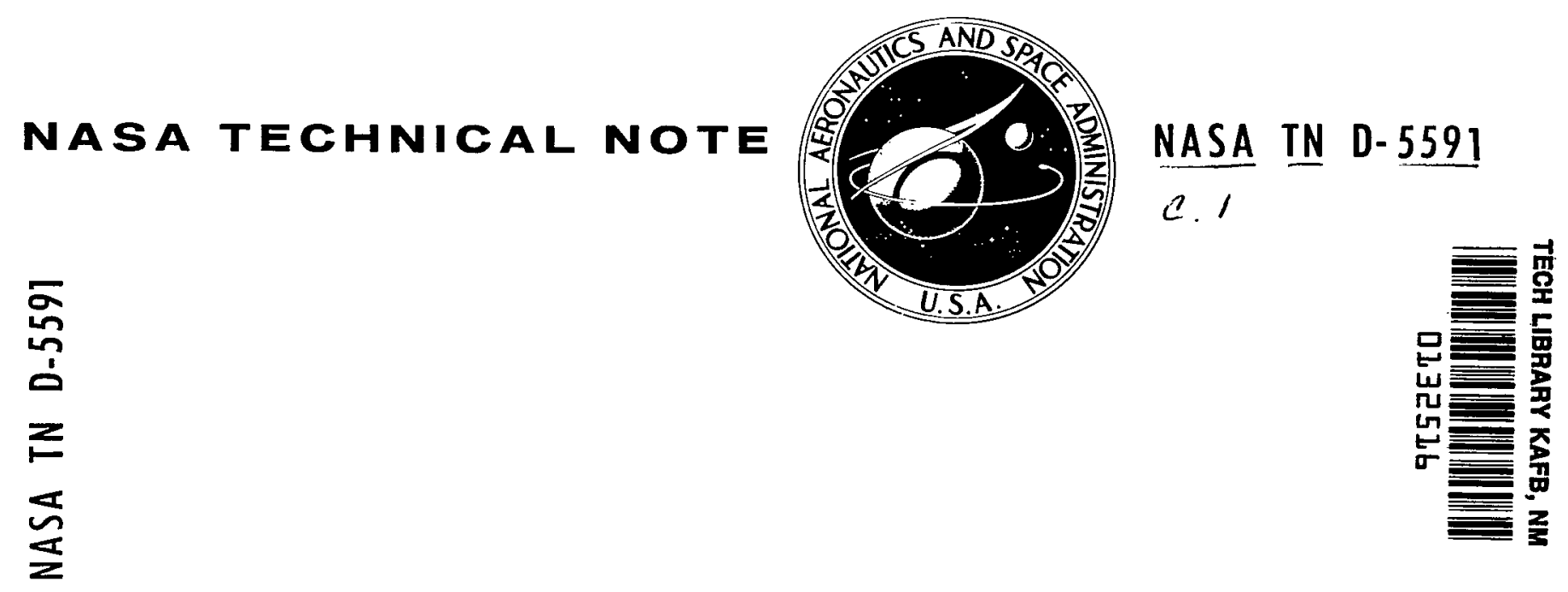

IOAN COPY: RETURN TO

KIRTIAND AFB, N MEX

\title{
A VARIATIONAL PRINCIPLE FOR MAGNETOHYDRODYNAMIC CHANNEL FLOW
}

by Norman C. Wenger

Lewis Research Center

Cleveland, Obio

NATIONAL AERONAUTICS AND SPACE ADMINISTRATION - WASHINGTON, D. C. - DECEMBER 1969 
1. Report No.

NASA TN D-5591

4. Title and Subtitle

A VARIATIONAL PRINCIPLE FOR MAGNETOHYDRODYNAMIC CHANNEL FLOW

7. Author(s)

Norman C. Wenger

9. Performing Organization Name and Address

Lewis Research Center

National Aeronautics and Space Administration

Cleveland, Ohio 44135

12. Sponsoring Agency Name and Address

National Aeronautics and Space Administration

Washington, D.C. 20546

15. Supplementary Notes

16. Abstract

A variational formulation is presented for a class of magnetohydrodynamic (MHD) channel flow problems. This formulation yields solutions for the fluid velocity and the induced electric potential in a channel with a uniform transverse static magnetic field. The channel cross section is constant but arbitrary, and the channel walls can be either insulators or conductors with finite electrical conductivity. Electric currents are permitted to enter and leave the channel walls so that the solutions are suitable for MHD generator and pump applications. An example of a square channel with conducting walls is solved as an illustration.

17. Key Words (Suggested by Author(s)) Magnetohydrodynamic flow Flow distribution Calculus of variations Channel flow

19. Security Clossif. (of this report) Unclassified 20. Security Clossif. (of this poge) Unclassified
18. Distribution Stotement

Unclassified - unlimited

*For sale by the Clearinghouse for Federal Scientific and Technical Information Springfield, Virginia 22151 
SUMMARY ................................ 1

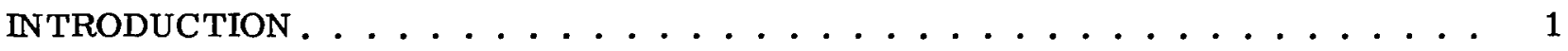

THE MODEL. ............................... 2

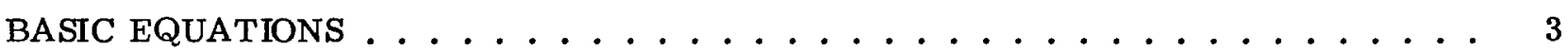

VARIATIONAL EXPRESSION . . . . . . . . . . . . . . . . . . . 7

PHYSICAL SIGNIFICANCE OF VARIATIONAL EXPRESSION . . . . . . . . . . . 11

EXAMPLE: SQUARE CHANNEL WITH CONDUCTING WALLS . . . . . . . . . . 14

Variational Solution........................ 14

Comparison of Results . . . . . . . . . . . . . . . . . . . 19

CONCLUDING REMARKS . . . . . . . . . . . . . . . . . . . . 22

APPENDLX - SYMBOLS........................... 23

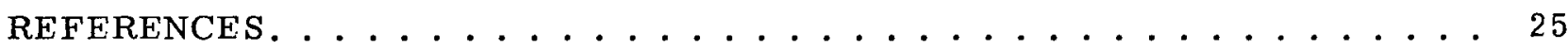




\title{
A VARIATIONAL PRINCIPLE FOR MAGNETOHYDRODYNAMIC CHANNEL FLOW
}

\author{
by Norman C. Wenger \\ Lewis Research Center
}

\begin{abstract}
SUMMARY
A variational formulation is presented for a class of magnetohydrodynamic (MHD) channel flow problems. This formulation yields solutions for the fluid velocity and the induced electric potential in a channel with a uniform transverse static magnetic field. The channel cross section is constant but arbitrary, and the channel walls can be either insulators or conductors with finite electrical conductivity. Electric currents are permitted to enter and leave the channel walls so that the solutions are suitable for MHD generator and pump applications. An example of a square channel with conducting walls is solved as an illustration.
\end{abstract}

\section{INTRODUCTION}

The study of magnetohydrodynamic (MHD) channel flow has received considerable attention in the past decade. This interest has been motivated by three principle applications; the MHD generator, the MHD pump, and the electromagnetic flowmeter.

The general model that is normally considered in these studies consists of an infinitely long channel of constant cross section with a uniform static magnetic field applied transverse to the axis of the channel. The walls of the channel are either insulators, conductors, or a combination of insulators and conductors depending on the intended application.

For example, in the MHD generator and pump cases, the channel cross section is normally rectangular with insulated walls perpendicular to the magnetic field and conducting walls parallel to the magnetic field. For the electromagnetic flowmeter case, the channel cross section is normally circular with conducting walls.

In order to carry out an analytical solution for MHD channel flow, it is generally necessary to make simplifying assumptions such as requiring the channel walls to be either perfect conductors or perfect insulators or requiring the channel walls to be very thin. These and other simplifications often greatly limit the usefulness of the results. 
This is particularly true for the electromagnetic flowmeter case since the thin wall approximation is often not valid for liquid metal applications and the wall conductivity is neither zero nor infinite. In addition, many analytical solutions give results in the form of infinite series which converge poorly for the large values of the static magnetic field that are encountered in practice.

To alleviate some of these difficulties, Tani (ref. 1) developed a variational formulation for the solution of MHD channel flow problems. His formulation gives solutions for the velocity profile and the induced magnetic field distribution in the channel for an arbitrary channel cross section. It requires, however, that the channel walls be either perfect conductors or insulators and that the admissible functions for the velocity and induced magnetic field satisfy appropriate boundary conditions.

In this report, a variational formulation is presented that gives solutions for the velocity profile and the electric potential distribution in a channel of arbitrary cross section. It also gives solutions for the electric potential distribution in the channel walls. The walls of the channel can be a combination of insulators and conductors but the conductors may have a finite conductivity. In addition, the admissible functions for the velocity and potential need not satisfy any prescribed boundary conditions. Moreover, the formulation is sufficiently general to allow electric currents to enter and leave the channel walls so that the solutions obtained are suitable for the MHD generator and pump applications.

The report concludes with an example that consists of a square channel with conducting walls of finite conductivity.

\section{THE MODEL}

A cross section of a generalized channel is shown in figure 1. It consists of the fluid duct $S_{f}$ bounded by the conducting walls $S_{c}$ and the insulated walls $S_{i}$. The contours $C_{f c}$ and $C_{f i}$ denote the fluid-conducting wall interface and the fluid-insulated wall interface, respectively. The contour $\mathrm{C}_{\mathrm{co}}$ denotes the outer edge of the conducting wall. The vector $\hat{n}$ is the unit normal to the contours with the positive direction as shown.

The applied static magnetic field $B_{0}$ is parallel to the $x$-axis and is uniform with respect to $y$ and $z$. The applied or generated current density at the outer edge of the conducting wall $\mathrm{J}_{\mathbf{a}}$ is considered positive when directed outward. It is assumed that the net current entering the channel cross section due to $\mathrm{J}_{\mathrm{a}}$ is zero, so that the twodimensional features of the model are retained. 


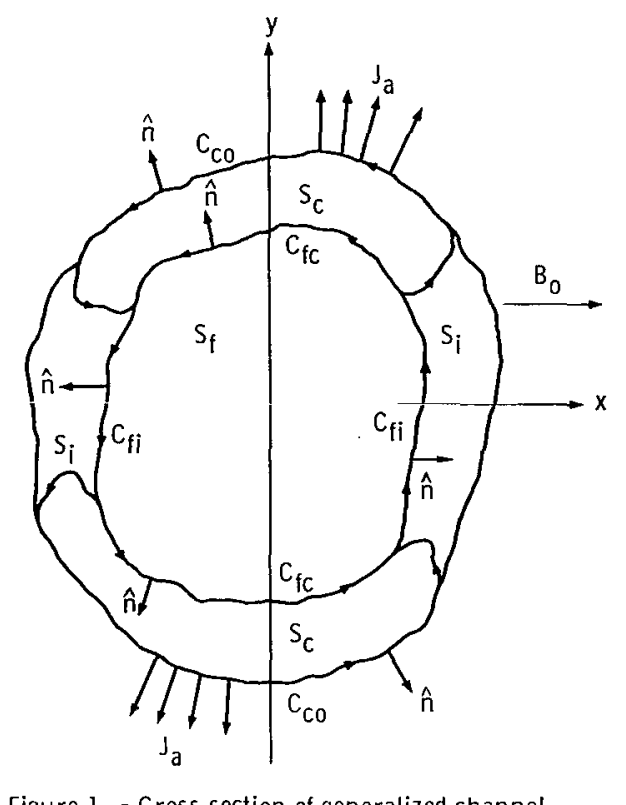

Figure 1. - Cross section of generalized channel.

\section{BASIC EQUATIONS}

The basic equations to be used are the standard MHD equations for steady-state conditions which consist of Maxwell's equations, the momentum transport equation, and the generalized Ohm's law. These are

$$
\begin{gathered}
\nabla \times \vec{E}=\overrightarrow{0} \\
\nabla \times \vec{B}=\mu_{0} \vec{J} \\
\nabla \cdot \vec{B}=0 \\
\rho(\vec{V} \cdot \nabla) \vec{V}=-\nabla p+\vec{J} \times \vec{B}+\eta \nabla^{2} \vec{V} \\
\vec{J}=\sigma_{f}(\vec{E}+\vec{V} \times \vec{B})
\end{gathered}
$$

where $\vec{E}, \vec{B}, \vec{J}$, and $\mu_{o}$ are the electric field intensity, magnetic flux density, electric current density, and magnetic permeability of free space, respectively; and $\overrightarrow{\mathrm{V}}, \rho, \eta$, $\sigma_{f}$, and $p$ are the fluid velocity, density, viscosity, electrical conductivity, and pressure, respectively.

Equations (1a) to (1e) are based on the assumptions that the fluid is homogeneous and incompressible, the magnetic permeability of the fluid is the same as that of free space, 
the electric charge density and Hall current are negligible, and the fluid flow is laminar. It may be argued that the last assumption of nonturbulent flow greatly limits the usefulness of the results since many flows in practice are turbulent. However, it has been found experimentally (ref. 2) that the onset of turbulence occurs at a much higher Reynolds number in MHD flow than for ordinary flow due to the suppression of turbulence by the static magnetic field.

The five basic equations (1a) to (1e) can be combined to give two coupled equations of second order. First, an electric potential $U$ which satisfies equation (1a) identically can be defined as

$$
\overrightarrow{\mathrm{E}}=-\nabla \mathrm{U}
$$

Next, substituting $\vec{J}$ from equation (1e) into (1b) and then taking the divergence of equation (1b) give

$$
\nabla^{2} \mathrm{U}=\nabla \cdot(\overrightarrow{\mathrm{V}} \times \overrightarrow{\mathrm{B}})
$$

where equation (2a) has been used to eliminate $\vec{E}$. The second equation can be obtained by substituting $\vec{J}$ from equation (1e) into (1d) and then eliminating $\vec{E}$ using equation (2a) giving

$$
\rho(\overrightarrow{\mathrm{V}} \cdot \nabla) \overrightarrow{\mathrm{V}}=-\nabla \mathrm{p}-\sigma_{\mathrm{f}}[\nabla \mathrm{U} \times \overrightarrow{\mathrm{B}}-(\overrightarrow{\mathrm{V}} \times \overrightarrow{\mathrm{B}}) \times \overrightarrow{\mathrm{B}}]+\eta \nabla^{2} \overrightarrow{\mathrm{V}}
$$

Due to the uniformity of the channel cross section and the applied magnetic field with respect to the $\mathrm{z}$-axis, all quantities in the basic equations are independent of $\mathrm{z}$ except for the pressure which is linear in $\mathrm{z}$ (ref. 3). In addition, it can be shown that the fluid velocity $\vec{V}$ has only a z-component $V_{z}$ and that $\vec{E}$ and $\vec{J}$ have only $x-$ and y-components (ref. 4). Furthermore, the total magnetic field $\vec{B}$ consists of the applied field $B_{0}$ in the $x$-direction and an induced field $B_{i}$ in the $z$-direction.

Since the velocity does not vary with $z$ and has only a $z$-component, the first term in equation (2c) vanishes. Expanding the vector cross products and taking the $\mathrm{z}$-component of equation $(2 \mathrm{c})$ along with equation $(2 \mathrm{~b})$ give the following governing equations:

$$
\begin{gathered}
\frac{\partial^{2} \mathrm{U}}{\partial \mathrm{x}^{2}}+\frac{\partial^{2} \mathrm{U}}{\partial \mathrm{y}^{2}}-\mathrm{B}_{\mathrm{o}} \frac{\partial \mathrm{V}_{\mathrm{z}}}{\partial \mathrm{y}}=0 \\
\frac{\partial^{2} \mathrm{~V}_{\mathrm{z}}}{\partial \mathrm{x}^{2}}+\frac{\partial^{2} \mathrm{~V}_{\mathrm{z}}}{\partial \mathrm{y}^{2}}-\frac{1}{\eta} \frac{\partial \underline{\mathrm{p}}}{\partial \mathrm{z}}+\frac{\sigma_{\mathrm{f}} \mathrm{B}_{\mathrm{o}}}{\eta} \frac{\partial \mathrm{U}}{\partial \mathrm{y}}-\frac{\sigma_{\mathrm{f}} \mathrm{B}_{\mathrm{o}}^{2}}{\eta} \mathrm{V}_{\mathrm{z}}=0
\end{gathered}
$$


These equations apply, of course, only in the fluid duct region $\mathrm{S}_{\mathrm{f}}$. In the conducting wall region $S_{c}$, equation (3a) applies with $V_{z}=0$. In the insulated wall region $S_{i}$, equation (3a) also applies with $V_{z}=0$ but it need not be solved.

Equations (3a) and (3b) are not unique governing equations in the sense that variables other than the velocity and electric potential can be selected for retention. Tani (ref. 1), for example, eliminated the electric potential but retained the velocity and the induced magnetic field yielding a different but equivalent set of governing equations.

In addition to the basic equations, appropriate boundary conditions must be specified to determine the solution uniquely. These conditions are

$$
\begin{gathered}
\left.V_{\mathrm{z}}\right|_{\mathrm{f}}=0 \quad \text { on } \mathrm{C}_{\mathrm{fc}} \text { and } \mathrm{C}_{\mathrm{fi}} \\
\left.\mathrm{U}\right|_{\mathrm{f}}-\left.\mathrm{U}\right|_{\mathrm{w}}=0 \quad \text { on } \mathrm{C}_{\mathrm{fc}} \\
\left.\sigma_{\mathrm{f}} \nabla \mathrm{U} \cdot \hat{\mathrm{n}}\right|_{\mathrm{f}}-\left.\sigma_{\mathrm{w}} \nabla \mathrm{U} \cdot \hat{\mathrm{n}}\right|_{\mathrm{w}}=0 \\
\left.\sigma_{\mathrm{f}} \nabla \mathrm{U} \cdot \hat{\mathrm{n}}\right|_{\mathrm{f}}=0 \\
\left.\sigma_{\mathrm{w}} \nabla \mathrm{U} \cdot \hat{\mathrm{n}}\right|_{\mathrm{w}}+\mathrm{J}_{\mathrm{a}}=0
\end{gathered}
$$

where $\left.\right|_{f}$ and $\left.\right|_{\mathrm{w}}$ refer to evaluating the quantity on the fluid or wall side of the contour, respectively.

The boundary condition equations (4a) to (4e) require the following:

(1) The fluid velocity must vanish on the fluid-wall interfaces $\mathrm{C}_{\mathrm{fc}}$ and $\mathrm{C}_{\mathrm{fi}}$.

(2) The electric potential must be continuous across the fluid-conducting wall interface $\mathrm{C}_{\mathrm{fc}}$.

(3) The component of the electric current normal to the fluid-conducting wall interface $\mathrm{C}_{\mathrm{fc}}$ must be continuous.

(4) The component of the electric current normal to the fluid-insulated wall interface $C_{f i}$ must vanish.

(5) The component of the electric current normal to the outer edge of the conducting wall $\mathrm{C}_{\text {co }}$ must equal the applied or generated current $\mathrm{J}_{\mathrm{a}}$.

In solving the equations, it is convenient to work with dimensionless quantities. This can easily be accomplished by defining $\mathrm{L}$ and $\mathrm{V}_{\mathrm{o}}$ to be a characteristic length and 
characteristic velocity of the channel. Let

$$
\begin{aligned}
& X=\frac{x}{L}, Y=\frac{y}{L}, Z=\frac{z}{L} \quad \text { dimensionless coordinates } \\
& \mathrm{W}=\frac{\mathrm{U}}{\mathrm{B}_{\mathrm{O}} \mathrm{L} \mathrm{V}_{\mathrm{O}}} \quad \text { dimensionless potential } \\
& \mathrm{V}=\frac{\mathrm{V}_{\mathrm{z}}}{\mathrm{V}_{\mathrm{O}}} \quad \text { dimensionless velocity } \\
& M=B_{0} L \sqrt{\frac{\sigma_{f}}{\eta}} \quad \text { Hartmann number } \\
& \mathrm{P}_{\mathrm{O}}=\frac{-\mathrm{L}^{2}}{\eta \mathrm{V}_{\mathrm{O}}} \frac{\partial \mathrm{p}}{\partial \mathrm{z}} \quad \text { dimensionless pressure gradient } \\
& J_{0}=\frac{J_{a}}{B_{0} V_{0} \sigma_{w}} \quad \text { dimensionless applied or generated current } \\
& \gamma=\frac{\sigma_{\mathrm{w}}}{\sigma_{\mathrm{f}}} \quad \text { ratio of wall-to-fluid conductivity }
\end{aligned}
$$

Combining equations (5a) to $(5 \mathrm{~g})$ with equations (3a) and ( $3 b$ ) yields the following set of equations in dimensionless form:

$$
\begin{gathered}
\frac{\partial^{2} \mathrm{~W}}{\partial \mathrm{X}^{2}}+\frac{\partial^{2} \mathrm{~W}}{\partial \mathrm{Y}^{2}}-\frac{\partial \mathrm{V}}{\partial \mathrm{Y}}=0 \quad \text { on } \mathrm{S}_{\mathrm{f}} \\
\frac{\partial^{2} \mathrm{~V}}{\partial \mathrm{X}^{2}}+\frac{\partial^{2} \mathrm{~V}}{\partial \mathrm{Y}^{2}}+\mathrm{P}_{\mathrm{o}}+\mathrm{M}^{2} \frac{\partial \mathrm{W}}{\partial \mathrm{Y}}-\mathrm{M}^{2} \mathrm{~V}=0 \quad \text { on } \mathrm{S}_{\mathrm{f}} \\
\frac{\partial^{2} \mathrm{~W}}{\partial_{\mathrm{X}}^{2}}+\frac{\partial^{2} \mathrm{~W}}{\partial^{2}}=0 \quad \text { on } \mathrm{S}_{\mathrm{C}}
\end{gathered}
$$


Likewise, combining equations (5a) to $(5 \mathrm{~g})$ with equations (4a) to (4e) gives the following set of dimensionless boundary condition equations:

$$
\begin{aligned}
& \left.\mathrm{V}\right|_{\mathrm{f}}=0 \quad \text { on } \mathrm{C}_{\mathrm{fc}} \text { and } \mathrm{C}_{\mathrm{fi}} \\
& \left.w\right|_{f}-\left.w\right|_{w}=0 \quad \text { on } C_{f c} \\
& \frac{1}{\sqrt{1+\left(\frac{d Y}{d X}\right)^{2}}}\left(\frac{d Y}{d X} \frac{\partial W}{\partial X}-\frac{\partial W}{\partial Y}\right)\left|-\frac{\gamma}{\sqrt{1+\left(\frac{d Y}{d X}\right)^{2}}}\left(\frac{d Y}{d X} \frac{\partial W}{\partial X}-\frac{\partial W}{\partial Y}\right)\right|_{W}=0 \quad \text { on } C_{f c} \\
& \left.\frac{1}{\sqrt{1+\left(\frac{d Y}{d X}\right)^{2}}}\left(\frac{d Y}{d X} \frac{\partial W}{\partial X}-\frac{\partial W}{\partial Y}\right)\right|_{f}=0 \quad \text { on } C_{f i} \\
& \left.\frac{1}{\sqrt{1+\left(\frac{d Y}{d X}\right)^{2}}}\left(\frac{d Y}{d X} \frac{\partial W}{\partial X}-\frac{\partial W}{\partial Y}\right)\right|_{W}-J_{o}=0 \quad \text { on } C_{c o}
\end{aligned}
$$

The unit normal vector $\hat{\mathrm{n}}$ has been replaced by

$$
\hat{\mathrm{n}}=\frac{-\frac{d Y}{d X} \hat{\mathrm{a}}_{\mathrm{x}}+\hat{\mathrm{a}}_{\mathrm{y}}}{\sqrt{1+\left(\frac{\mathrm{dY}}{d X}\right)^{2}}}
$$

where $\hat{a}_{x}$ and $\hat{a}_{y}$ are the unit vectors in the $X$ - and $Y$-directions, respectively. The sign of the square root must be selected so that the positive direction for $\hat{n}$ is as shown in figure 1.

\section{VARIATIONAL EXPRESSION}

The goal of this section is to construct a functional of the dependent variables $V$ 
and $W$ so that the associated Euler-Lagrange equations are the basic governing equations (6a) to $(6 \mathrm{c})$ and where the corresponding natural boundary conditions are the prescribed boundary condition equations $(6 \mathrm{~d})$ to $(6 \mathrm{~h})$. This construction is performed by summing terms that are obtained by multiplying each governing equation and boundary condition equation by a suitable function and then integrating over the corresponding area or contour where the equation is valid.

Let $\delta \mathrm{V}$ and $\delta \mathrm{W}$ be arbitrary functions of $\mathrm{X}$ and $\mathrm{Y}$ that are continuous with piecewise continuous first derivatives. The integrals

$$
\begin{aligned}
& \mathrm{I}_{1} \equiv 2 \int_{\mathrm{S}_{\mathrm{f}}}\left[\frac{\partial^{2} \mathrm{~V}}{\partial \mathrm{X}^{2}}+\frac{\partial^{2} \mathrm{~V}}{\partial \mathrm{Y}^{2}}+\mathrm{P}_{\mathrm{o}}+\mathrm{M}^{2} \frac{\partial \mathrm{W}}{\partial \mathrm{Y}}-\mathrm{M}^{2} \mathrm{~V}\right] \delta \mathrm{V} d \mathrm{X} d \mathrm{Y} \\
& \mathrm{I}_{2} \equiv 2 \mathrm{M}^{2} \int_{\mathrm{S}_{\mathrm{f}}}\left[\frac{\partial^{2} \mathrm{~W}}{\partial \mathrm{X}^{2}}+\frac{\partial^{2} \mathrm{~W}}{\partial \mathrm{Y}^{2}}-\frac{\partial \mathrm{V}}{\partial \mathrm{Y}}\right] \delta \mathrm{W} \mathrm{dX} d \mathrm{Y} \\
& \mathrm{I}_{3} \equiv 2 \gamma \mathrm{M}^{2} \int_{\mathrm{S}_{\mathrm{C}}}\left[\frac{\partial^{2} \mathrm{~W}}{\partial \mathrm{X}^{2}}+\frac{\partial^{2} \mathrm{~W}}{\partial \mathrm{Y}^{2}}\right] \delta \mathrm{W} d \mathrm{X} d \mathrm{Y}
\end{aligned}
$$

are identically zero for any $\delta \mathrm{V}$ and $\delta \mathrm{W}$ since the quantities in brackets [ ] are identically zero by virtue of equations (6a) to (6c).

Four additional integral expressions that are identically zero can be obtained from the boundary condition equations $(6 \mathrm{~d})$ to $(6 \mathrm{~h})$ by integrating along appropriate contours. Recalling that the differential length along a contour is given by $\sqrt{1+(d Y / d X})^{2} d X$, these integral expressions can be defined as

$$
\begin{gathered}
\mathrm{I}_{4} \equiv-2 \mathrm{M}^{2} \int_{\mathrm{C}_{\mathrm{fc}}}\left[\left.\left(\frac{\partial \mathrm{W}}{\partial \mathrm{X}} \mathrm{dY}-\frac{\partial \mathrm{W}}{\partial \mathrm{Y}} \mathrm{dX}\right)\right|_{\mathrm{f}}-\left.\gamma\left(\frac{\partial \mathrm{W}}{\partial \mathrm{X}} \mathrm{dY}-\frac{\partial \mathrm{W}}{\partial \mathrm{Y}} \mathrm{dX}\right)\right|_{\mathrm{W}}\right] \delta \mathrm{W} \\
\mathrm{I}_{5} \equiv-\left.2 \mathrm{M}^{2}\left[\frac{\partial \mathrm{W}}{\partial \mathrm{X}} \mathrm{dY}-\frac{\partial \mathrm{W}}{\partial \mathrm{Y}} \mathrm{dX}\right]\right|_{\mathrm{f}} \delta \mathrm{W}
\end{gathered}
$$




$$
\begin{gathered}
I_{6} \equiv-\left.2 \gamma M^{2} \int_{C_{C O}}\left[\frac{\partial W}{\partial X} d Y-\frac{\partial W}{\partial Y} d X-J_{0} \sqrt{1+\left(\frac{d Y}{d X}\right)^{2}} d X\right]\right|_{W} \delta W \\
\left.I_{7} \equiv 2 \int_{\mathrm{C}_{f^{+}}+C_{f i}}^{[V]}\left(\frac{\partial \delta V}{\partial X} d Y-\frac{\partial \delta V}{\partial Y} d X-M^{2} \delta W d X\right)\right|_{f}
\end{gathered}
$$

These integrals vanish since the quantities in brackets are zero by virtue of the boundary condition equations $(6 \mathrm{~d})$ to $(6 \mathrm{~h})$.

The symbol $\delta$ can be defined as the variation operator so that the functions $\delta \mathrm{V}$ and $\delta W$ can be considered as the variation of $\mathrm{V}$ and $\mathrm{W}$, respectively. In addition, the $\delta$ operator commutes with $\partial / \partial \mathrm{X}$ and $\partial / \partial \mathrm{Y}$ since $\mathrm{X}$ and $\mathrm{Y}$ are independent variables. Using these properties along with Green's lemma, the integrals $I_{1}$ to $I_{7}$ can be integrated by parts and combined to give

$$
\sum_{n=1}^{7} I_{n}=\delta F
$$

where

$$
\begin{aligned}
& F \equiv \int_{S_{f}}\left\{2 P_{0} V-\left(\frac{\partial V}{\partial X}\right)^{2}-\left(\frac{\partial V}{\partial Y}\right)^{2}-M^{2}\left[V^{2}+\left(\frac{\partial W}{\partial X}\right)^{2}+\left(\frac{\partial W}{\partial Y}\right)^{2}-2 V \frac{\partial W}{\partial Y}\right]\right\} d X d Y \\
& -\gamma \mathbf{M}^{2} \int_{\mathrm{S}_{\mathrm{C}}}\left[\left(\frac{\partial \mathrm{W}}{\partial \mathrm{X}}\right)^{2}+\left(\frac{\partial \mathrm{W}}{\partial \mathrm{Y}}\right)^{2}\right] \mathrm{dX} d \mathrm{Y}+\left.2 \int_{\mathrm{C}_{\mathrm{fc}}+\mathrm{C}_{\mathrm{fi}}} \mathrm{V}\left[\frac{\partial \mathrm{V}}{\partial \mathrm{X}} \mathrm{dY}-\frac{\partial \mathrm{V}}{\partial \mathrm{Y}} \mathrm{dX}\right]\right|_{\mathrm{f}}
\end{aligned}
$$

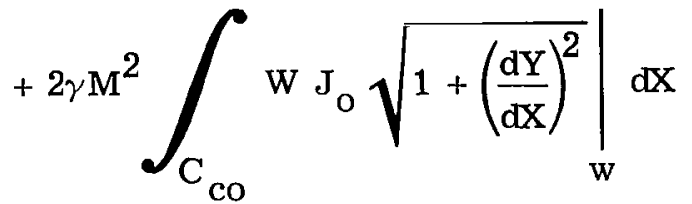

Since each $I_{n}(n=1, \ldots, 7)$ is identically zero, the variation of the functional $F$ is zero. Thus, $\mathrm{F}$ is stationary; that is, first order changes in $\mathrm{V}$ and $\mathrm{W}$ about their true 
values produce only second order changes in $\mathbf{F}$.

Another way of stating this result is that of all functions that are continuous with piecewise continuous first derivatives, the particular pair of functions for $\mathrm{V}$ and $\mathrm{W}$ that make $F$ stationary, satisfy both the basic equations (6a) to (6c) and the boundary condition equations (6d) to $(6 \mathrm{~h})$ and, hence, are the desired solutions.

Even though $\mathbf{F}$ was shown to be stationary, it does not necessarily mean that $\mathbf{F}$ has a maximum or minimum at the true solution for $V$ and $W$. For example, as $V$ and $W$ are varied from their true values, $F$ may always increase, always decrease, or either increase or decrease depending on how $V$ and $W$ are varied. To determine which case corresponds to the $F$ under consideration the quantity $F(V+\delta V, W+\delta W)-$ $\mathrm{F}(\mathrm{V}, \mathrm{W})$ is computed giving

$$
\begin{aligned}
& F(V+\delta V, W+\delta W)-F(V, W)=2 \int\left\{\left[\frac{\partial^{2} V}{\partial X^{2}}+\frac{\partial^{2} V}{\partial Y^{2}}+P_{o}-M^{2} V+M^{2} \frac{\partial W}{\partial Y}\right] \delta V\right. \\
& \left.+\mathbf{M}^{2}\left[\frac{\partial^{2} \mathrm{~W}}{\partial \mathrm{X}^{2}}+\frac{\partial^{2} \mathrm{~W}}{\partial \mathrm{Y}^{2}}-\frac{\partial \mathrm{V}}{\partial \mathrm{Y}}\right] \delta \mathrm{W}\right\} d \mathrm{X} d \mathrm{Y}+2 \gamma \mathrm{M}^{2} \int\left[\frac{\partial^{2} \mathrm{~W}}{\partial \mathrm{X}^{2}}+\frac{\partial^{2} \mathrm{~W}}{\partial \mathrm{Y}^{2}}\right] \delta \mathrm{W} d \mathrm{X} d \mathrm{Y} \\
& -2 M^{2} \int\left[\left.\left(\frac{\partial W}{\partial X} d Y-\frac{\partial W}{\partial Y} d X\right)\right|_{f}-\left.\gamma\left(\frac{\partial W}{\partial X} d Y-\frac{\partial W}{\partial Y} d X\right)\right|_{W}\right] \delta W \\
& -2 \mathrm{M}^{2} \int_{\mathrm{C}_{\mathrm{fi}}}\left[\frac{\partial W}{\partial \mathrm{X}} \mathrm{dY}-\frac{\partial W}{\partial \mathrm{Y}} d \mathrm{X}\right] \delta \mathrm{W} \mid-2 \gamma \mathrm{M}^{2} \int_{\mathrm{f}}\left[\left(\frac{\partial W}{\partial \mathrm{X}} \mathrm{dY}-\frac{\partial W}{\partial \mathrm{Y}} d \mathrm{X}\right)\right. \\
& \left.-J_{o} \sqrt{1+\left(\frac{d \mathrm{Y}}{d X}\right)^{2}} d X\right]\left.\delta \mathrm{W}\right|_{\mathrm{W}}+2 \int_{\mathrm{C}_{\mathrm{fc}}+\mathrm{C}_{\mathrm{fi}}}[\mathrm{V}]\left(\frac{\partial \delta \mathrm{V}}{\partial \mathrm{X}} \mathrm{dY}-\frac{\partial \delta \mathrm{V}}{\partial \mathrm{Y}} \mathrm{dX}-\mathrm{M}^{2} \delta \mathrm{W} d \mathrm{XX}\right) \mid \\
& -\int\left\{\left(\frac{\partial \delta V}{\partial X}\right)^{2}+\left(\frac{\partial \delta V}{\partial Y}\right)^{2}+M^{2}\left(\frac{\partial \delta W}{\partial X}\right)^{2}+M^{2}\left(\frac{\partial \delta W}{\partial Y}+\delta V\right)^{2}\right\} d X d Y \\
& -\gamma \mathbf{M}^{2} \int_{\mathrm{S}_{\mathrm{C}}}\left\{\left(\frac{\partial \delta \mathrm{W}}{\partial \mathrm{X}}\right)^{2}+\left(\frac{\partial \delta \mathrm{W}}{\partial \mathrm{Y}}\right)^{2}\right\} d \mathrm{X} d \mathrm{Y}+\left.2 \int_{\mathrm{C}_{\mathrm{fc}}+\mathrm{C}_{\mathrm{fi}}}\left(\frac{\partial \delta \mathrm{V}}{\partial \mathrm{X}} \mathrm{dY}-\frac{\partial \delta \mathrm{V}}{\partial \mathrm{Y}} \mathrm{dX}\right) \delta \mathrm{V}\right|_{\mathrm{f}}
\end{aligned}
$$


A careful examination of equation (9) reveals that the first six integrals vanish because the quantities in brackets [ ] are identically zero. The remaining integrals are of second order in $\delta \mathrm{V}$ and $\delta \mathrm{W}$. This result is not surprising since $F$ was constructed so that all first order terms in $\delta \mathrm{V}$ and $\delta \mathrm{W}$ vanished. Of the three remaining integrals in equation (9), two are negative definite and the last can be of either sign. Thus, $F$ has neither a minimum nor maximum at the true values for $V$ and $W$. However, if the class of admissible functions for $\mathrm{V}$ and $\mathrm{W}$ is restricted so that the last integral must vanish, then $F$ corresponds to a maximum at the true values for $V$ and $W$ since then $F(V+\delta V, W+\delta W)-F(V, W) \leq 0$.

A study of the last integral in equation (9) reveals that the proper restriction to impose is that $V$ must vanish on the contours $C_{f c}$ and $C_{f i}$. An alternate choice which also makes the last integral vanish is to specify $\partial \mathrm{V} / \partial \mathrm{n}$ on $\mathrm{C}_{\mathrm{fc}}$ and $\mathrm{C}_{\mathrm{fi}}$. This choice is useless, however, since it would require solving the problem another way first to determine the correct value for $\partial \mathrm{V} / \partial \mathrm{n}$.

Requiring $\mathrm{V}$ to vanish on $\mathrm{C}_{\mathrm{fc}}$ and $\mathrm{C}_{\mathrm{fi}}$ may provide a great simplification in many problems in obtaining approximate values for $\mathrm{V}$ and $\mathrm{W}$ since finding a maximum for $\mathrm{F}$ is of ten much easier than finding a stationary point. Moreover, requiring $\mathrm{V}$ to vanish on $\mathrm{C}_{\mathrm{fc}}$ and $\mathrm{C}_{\mathrm{fi}}$ completely eliminates one integral in the expression for $\mathrm{F}$ given by equation $(8 b)$.

Before a solution for $\mathrm{V}$ and $\mathrm{W}$ can be determined, values for $\mathrm{P}_{0}$ and $\mathrm{J}_{0}$ must be specified. The dimensionless pressure gradient $\mathrm{P}_{0}$ must be a constant as previously noted. The dimensionless current density $\mathrm{J}_{0}$, however, can be specified as a function of the coordinates along the contour $\mathrm{C}_{\mathrm{co}}$. Since the basic equations and boundary condition equations are linear in $\mathrm{V}, \mathrm{W}, \mathrm{P}_{0}$, and $\mathrm{J}_{\mathrm{O}}$, solutions for $\mathrm{V}$ and $\mathrm{W}$ can be obtained by superimposing solutions for $\mathbf{P}_{\mathrm{O}} \neq 0$ and $\mathrm{J}_{\mathrm{O}}=0$ with those for $\mathbf{P}_{\mathrm{O}}=0$ and $\mathrm{J}_{\mathrm{O}} \neq 0$.

To complete the study of the variational expression, it is desirable to determine its physical significance.

\section{PHYSICAL SIGNIFICANCE OF VARIATIONAL EXPRESSION}

Consider the power or energy balance that exists in MHD channel flow. The power per unit length that is supplied to the fluid by the pressure gradient $P_{\Delta p}$ is given by

$$
\mathbf{P}_{\Delta \mathrm{p}}=-\int_{\mathrm{S}_{\mathrm{f}}} \frac{\partial \mathrm{p}}{\partial \mathrm{z}} \mathrm{V}_{\mathrm{z}} \mathrm{dx} d \mathrm{x}=\eta \mathrm{V}_{\mathrm{o}}^{2} \int_{\mathrm{S}_{\mathrm{f}}} \mathbf{P}_{\mathrm{o}} \mathrm{V} \mathrm{dX} \mathrm{dY}
$$

If this quantity is negative, it simply means that the channel is acting as a pump. 
The dissipative terms consist of the viscous losses in the fluid $\mathrm{P}_{\eta}$, the ohmic losses in the fluid $\mathbf{P}_{\sigma_{\mathbf{f}}}$, and the ohmic losses in the conducting walls $\mathbf{P}_{\sigma_{\mathrm{w}}}:$ Expressing each of these in terms of the power dissipated per unit length along the channel gives

$$
\begin{aligned}
& \mathbf{P}_{\eta}=-\int_{\mathrm{S}_{\mathrm{f}}} \eta\left(\frac{\partial^{2} \mathrm{~V}_{\mathrm{z}}}{\partial \mathrm{x}^{2}}+\frac{\partial^{2} \mathrm{~V}_{\mathrm{z}}}{\partial \mathrm{y}^{2}}\right) \mathrm{v}_{\mathrm{z}} \mathrm{dx} d \mathrm{y}=\eta \mathrm{V}_{\mathrm{o}}^{2} \int_{\mathrm{S}_{\mathrm{f}}}\left[\left(\frac{\partial \mathrm{V}}{\partial \mathrm{X}}\right)^{2}+\left(\frac{\partial \mathrm{V}}{\partial \mathrm{Y}}\right)^{2}\right] d \mathrm{X} d \mathrm{Y}
\end{aligned}
$$

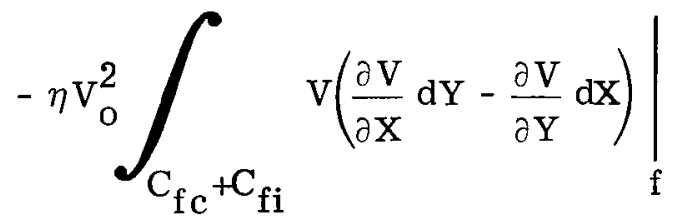

$$
\begin{aligned}
& \mathrm{P}_{\sigma_{\mathrm{f}}}=\sigma_{\mathrm{f}} \int_{\mathrm{S}_{\mathrm{f}}}\left|-\frac{\partial \mathrm{U}}{\partial \mathrm{x}} \hat{\mathrm{a}}_{\mathrm{x}}-\frac{\partial \mathrm{U}}{\partial \mathrm{y}} \hat{\mathrm{a}}_{\mathrm{y}}+\mathrm{V}_{\mathrm{z}} \mathrm{B}_{\mathrm{o}} \hat{\mathrm{a}}_{\mathrm{y}}\right|^{2} \mathrm{dx} \mathrm{dy} \\
& =\eta \mathrm{V}_{\mathrm{o}}^{2} \mathrm{M}^{2} \int_{\mathrm{S}_{\mathrm{f}}}\left[\left(\frac{\partial \mathrm{W}}{\partial \mathrm{X}}\right)^{2}+\left(\frac{\partial \mathrm{W}}{\partial \mathrm{Y}}-\mathrm{V}\right)^{2}\right] \mathrm{dX} \mathrm{dY} \\
& P_{\sigma_{w}}=\sigma_{w} \int_{S_{c}}\left|-\frac{\partial U}{\partial x} \hat{a}_{x}-\frac{\partial U}{\partial y} \hat{a}_{y}\right|^{2} d x d y \\
& =\eta \mathrm{V}_{\mathrm{o}}^{2} \gamma \mathrm{M}^{2} \int_{\mathrm{S}_{\mathrm{C}}}\left[\left(\frac{\partial \mathrm{W}}{\partial \mathrm{X}}\right)^{2}+\left(\frac{\partial \mathrm{W}}{\partial \mathrm{Y}}\right)^{2}\right] \mathrm{dX} \mathrm{dY}
\end{aligned}
$$

Equation (10b) reveals that the viscous losses in the fluid can be split into two parts; the volume losses $P_{\eta_{\mathrm{V}}}$ and the surface losses $\mathrm{P}_{\eta_{\mathrm{S}}}$ where 


$$
\begin{gathered}
\mathrm{P}_{\eta_{\mathrm{v}}}=\eta \mathrm{V}_{\mathrm{o}}^{2} \int_{\mathrm{S}_{\mathrm{f}}}\left[\left(\frac{\partial \mathrm{V}}{\partial \mathrm{X}}\right)^{2}+\left(\frac{\partial \mathrm{V}}{\partial \mathrm{Y}}\right)^{2}\right] \mathrm{dX} d \mathrm{Y} \\
\mathrm{P}_{\eta_{\mathrm{S}}}=-\left.\eta \mathrm{V}_{\mathrm{o}}^{2} \int_{\mathrm{C}_{\mathrm{fc}}+\mathrm{C}_{\mathrm{fi}}} \mathrm{v}\left(\frac{\partial \mathrm{V}}{\partial \mathrm{X}} \mathrm{dY}-\frac{\partial \mathrm{V}}{\partial \mathrm{Y}} \mathrm{dX}\right)\right|_{\mathrm{f}}
\end{gathered}
$$

The surface losses are zero when the boundary condition is imposed that requires $\mathrm{V}$ to vanish on $\mathrm{C}_{\mathrm{fc}}$ and $\mathrm{C}_{\mathrm{fi}}$.

The remaining term to be considered is the loss due to the current $J_{a}$. Since $J_{a}$ is positive by definition when it is directed outward, the power that is supplied to an external load per unit length of the channel $\mathrm{P}_{\mathrm{J}_{\mathrm{a}}}$ is given by

$$
\mathrm{P}_{\mathrm{J}_{\mathrm{a}}}=-\int_{\mathrm{C}_{\mathrm{co}}} \mathrm{U} \mathrm{J}_{\mathrm{a}} \sqrt{1+\left(\frac{\mathrm{dy}}{\mathrm{dx}}\right)^{2}} \mathrm{dx}=-\eta \mathrm{V}_{\mathrm{o}}^{2} \gamma \mathrm{M}^{2} \int_{\mathrm{C}_{\mathrm{CO}}} \mathrm{W} \mathrm{J}_{\mathrm{o}} \sqrt{1+\left(\frac{\mathrm{dY}}{\mathrm{dX}}\right)^{2}} \mathrm{dX}
$$

If $\mathrm{P}_{\mathrm{J}_{\mathrm{a}}}$ is negative, it simply indicates that power is being supplied by an external source.

Since power is conserved, the power balance for the channel can be expressed as

$$
\mathbf{P}_{\Delta \mathrm{p}}=\mathrm{P}_{\eta_{\mathrm{v}}}+\mathrm{P}_{\dot{\eta}_{\mathrm{s}}}+\mathrm{P}_{\sigma_{\mathrm{f}}}+\mathrm{P}_{\sigma_{\mathrm{w}}}+\mathrm{P}_{\mathrm{J}_{\mathrm{a}}}
$$

Comparing the expression for the functional $F$ given by equation ( $8 \mathrm{~b}$ ) with the various power dissipation terms given by equations (10a) to (10g) reveals that $F$ can be expressed as

$$
\eta \mathrm{V}_{\mathrm{o}}^{2} \mathrm{~F}=2 \mathrm{P} \Delta \mathrm{p}-\mathrm{P}_{\eta_{\mathrm{v}}}-\mathrm{P}_{\sigma_{\mathrm{f}}}-\mathrm{P}_{\sigma_{\mathrm{w}}}-2 \mathrm{P}_{\eta_{\mathrm{s}}}-2 \mathrm{P}_{\mathrm{J}_{\mathrm{a}}}
$$

A word of caution is in order at this point. The expression for $F$ given by equation (8b) is defined and valid for an arbitrary choice for $\mathrm{V}$ and $\mathrm{W}$. Likewise, the power dissipation terms $P_{\eta_{\mathrm{v}}}, \mathrm{P}_{\sigma_{\mathrm{f}}}$, etc., given by equations (10a) to (10g) are valid for arbitrary values for $\mathrm{V}$ and $\mathrm{W}$. Thus, equation (12) is valid, in general. However, equa- 
tion (11) which is the power balance for the channel is only valid for the correct solutions for $\mathrm{V}$ and $\mathrm{W}$.

As shown in the previous section, the stationary point for $F$ corresponds to the true solutions for $V$ and W. For these values only, equations (11) and (12) can be combined to give

$$
F_{s t}=\frac{P_{\Delta p}-P_{J_{a}}}{\eta V_{o}^{2}}
$$

where it has been recognized that $\mathbf{P}_{\eta_{\mathrm{S}}}$ vanishes for the true $V$. Thus, the stationary value of $F$ is proportional to the difference between the power supplied to the fluid by the pressure gradient and the electrical power delivered to an external load.

An important special case occurs for $\mathrm{J}_{\mathrm{a}}=0$ which yields

$$
F_{\text {st }}=\int_{S_{f}} P_{o} V d X d Y
$$

where $P_{\Delta p}$ has been replaced using equation (10a). Since the dimensionless pressure gradient $\mathrm{P}_{\mathrm{o}}$ is a constant, the stationary value for $\mathrm{F}$ is proportional to the average fluid velocity in the channel. This is a very important result since the average velocity, which is often the main quantity of interest, is proportional to a stationary quantity which can be computed to good accuracy.

If the boundary condition $\mathrm{V}=0$ on $\mathrm{C}_{\mathrm{fc}}$ and $\mathrm{C}_{\mathrm{fi}}$ is satisfied by all admissible functions, $F$ has a maximum at its stationary point as noted in the previous section. The maximum for $\mathrm{F}$ using a subset of the class of admissible functions for $\mathrm{V}$ and $\mathrm{W}$ will be less than the maximum for $F$ using the entire class of admissible functions. Thus, a lower limit for the average velocity can be easily found by using any admissible function.

\section{EXAMPLE: SQUARE CHANNEL WITH CONDUCTING WALLS}

\section{Variational Solution}

A square channel is shown in figure 2 using the dimensionless coordinates. The characteristic length for the channel $L$ has been chosen as one-half its height or width so that its inner corners are located at $(1,1),(1,-1),(-1,1)$, and $(-1,-1)$. The normalized wall thickness $t$ is the actual wall thickness divided by $L$. 


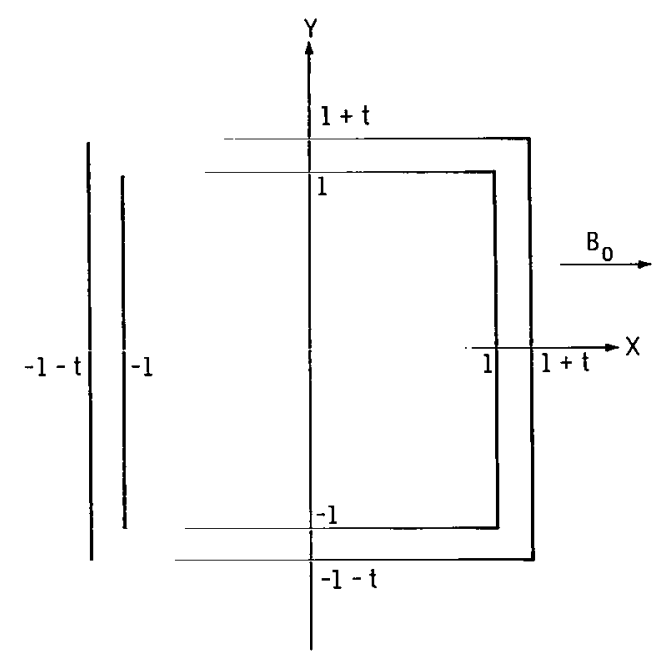

Figure 2. - Cross section of square channel with conducting walls.

Approximate solutions for the velocity and electric potential will be obtained using the Ritz technique. In this technique, the velocity and potential are expressed in terms of known functions of $\mathrm{X}$ and $\mathrm{Y}$ that approximate the true solution but contain adjustable parameters $\lambda_{1}, \ldots ., \lambda_{n}$. The approximate solutions for $V$ and $W$ are then substituted into the expression for $F$ given by equation ( $8 b)$ and the indicated integrations with respect to $\mathrm{X}$ and $\mathrm{Y}$ are performed. This leaves $\mathrm{F}$ as a function of the parameters $\lambda_{1}, \ldots, \lambda_{n}$ and the characteristic parameters of the channel $\mathrm{P}_{0}, \gamma, \mathrm{M}$, and $\mathrm{J}_{0}$. Assuming that $V$ vanishes at $X= \pm 1$ and $Y= \pm 1$ for all values of $\lambda_{1}, \ldots, \lambda_{n}$, the stationary value of $F$ can be found by maximizing $F$ with respect to $\lambda_{1}, \ldots, \lambda_{n}$. The corresponding values for $\lambda_{1}, \ldots, \lambda_{n}$ when substituted into the approximate functions for $\mathrm{V}$ and $\mathrm{W}$ will yield the closest approximations to the velocity and potential that are possible for the class of functions used.

In order to determine the accuracy of the solutions obtained using the Ritz technique, a sequence of approximations is normally used. In this method, a suitable, complete, infinite set of functions is selected such as sine or cosine harmonics, Bessel functions, etc., so that some linear combination of them is capable of representing the solution. For the MHD channel flow problem these functions must be capable of representing any continuous function with a piecewise continuous derivative over the channel cross section.

The procedure consists of first obtaining an approximate solution using a linear combination of a finite number of these functions where the adjustable parameters $\lambda_{1}, \ldots$. , $\lambda_{n}$ correspond to the coefficients of these functions. The problem is then repeatedly solved, each time increasing the number of functions used. By comparing the results from successive approximations, an estimate of the accuracy and convergence rate can be obtained. 
In many problems, however, much is already known about the solution so that the trial functions can be tailored to more accurately approximate the solution thereby reducing the number of adjustable parameters required. This alternate procedure does not allow the error in the approximation to be easily estimated but it is much easier to use computationally since fewer adjustable parameters are involved. This alternate procedure will be followed in this example.

The solution for the square channel will be determined for $P_{0}=1$ and $J_{0}=0$. Let the trial functions for $\mathrm{V}$ and $\mathrm{W}$ be given by

$$
\begin{array}{cl}
\mathrm{V}(\mathrm{X}, \mathrm{Y})=\mathrm{A}_{1}\left(1-\mathrm{X}^{\alpha}\right)\left(1-\mathrm{Y}^{\alpha}\right) & 0 \leq \mathrm{X} \leq 1 \\
\mathrm{~W}(\mathrm{X}, \mathrm{Y})=\left(\mathrm{C}_{1} \mathrm{Y}^{\beta_{1}}+\mathrm{C}_{2} \mathrm{Y}^{\beta}\right)\left(1+\mathrm{C}_{3} \mathrm{X}^{\beta}\right) & 0 \leq \mathrm{Y} \leq 1 \\
& 0 \leq \mathrm{X} \leq 1+\mathrm{t} \\
& 0 \leq 1+\mathrm{t}
\end{array}
$$

where $\mathrm{A}_{1}, \mathrm{C}_{1}, \mathrm{C}_{2}, \mathrm{C}_{3}, \alpha_{1}, \alpha_{2}, \beta_{1}, \beta_{2}$, and $\beta_{3}$ are adjustable parameters. Because of the symmetry of the problem, it is only necessary to specify $V$ and $W$ in the first quadrant. For other quadrants, $\mathrm{V}$ and $\mathrm{W}$ can be found using the relations $\mathrm{V}(\mathrm{X}, \mathrm{Y})=$ $\mathrm{V}(\mathrm{X},-\mathrm{Y})=\mathrm{V}(-\mathrm{X}, \mathrm{Y})$ and $\mathrm{W}(\mathrm{X}, \mathrm{Y})=\mathrm{W}(-\mathrm{X}, \mathrm{Y})=-\mathrm{W}(\mathrm{X},-\mathrm{Y})$. Since the admissible functions for $\mathrm{V}$ and $\mathrm{W}$ must be continuous with piecewise continuous derivatives, all exponents in equations (15a) and (15b) must be 1 or greater.

Trial functions of the form given by equations (15a) and (15b) have proven to be very useful in solving MHD channel flow problems of this type since the velocity profile, for example, can go from a parabolic $\left(\alpha_{1}=\alpha_{2}=2\right)$ to nearly slug flow $\left(\alpha_{1}, \alpha_{2}\right.$ large $)$ by merely varying two parameters.

Substituting equations (15a) and (15b) into the expression for $F$ given by equation ( $8 b$ ) yields after performing the integrations

$$
\mathrm{F}=[\psi]^{\mathrm{T}}[\mathrm{A}][\psi]-[\psi]^{\mathrm{T}}[\mathrm{D}]
$$

where

$$
[\psi]=\left[\begin{array}{l}
A_{1} \\
C_{1} \\
C_{2}
\end{array}\right] \quad[A]=\left[\begin{array}{ccc}
a_{11} & a_{12} & a_{13} \\
a_{12} & a_{22} & a_{23} \\
a_{13} & a_{23} & a_{33}
\end{array}\right] \quad[D]=\left[\begin{array}{c}
d_{1} \\
0 \\
0
\end{array}\right]
$$




$$
\begin{aligned}
& \mathrm{a}_{11}=-\frac{8 \alpha_{1}^{2} \alpha_{2}^{2}}{\left(\alpha_{2}+1\right)\left(2 \alpha_{1}-1\right)\left(2 \alpha_{2}+1\right)}-\frac{8 \alpha_{1}^{2} \alpha_{2}^{2}}{\left(\alpha_{1}+1\right)\left(2 \alpha_{2}-1\right)\left(2 \alpha_{1}+1\right)} \\
& -\frac{16 \mathrm{M}^{2} \alpha_{1}^{2} \alpha_{2}^{2}}{\left(\alpha_{1}+1\right)\left(2 \alpha_{1}+1\right)\left(\alpha_{2}+1\right)\left(2 \alpha_{2}+1\right)} \\
& \mathrm{a}_{12}=\frac{4 \mathrm{M}^{2} \alpha_{1} \alpha_{2}}{\beta_{1}+\alpha_{2}}\left[\frac{1}{\alpha_{1}+1}+\frac{\mathrm{C}_{3}}{\left(\beta_{3}+1\right)\left(\beta_{3}+\alpha_{1}+1\right)}\right] \\
& \mathrm{a}_{13}=\frac{4 \mathrm{M}^{2} \alpha_{1} \alpha_{2}}{\beta_{2}+\alpha_{2}}\left[\frac{1}{\alpha_{1}+1}+\frac{\mathrm{C}_{3}}{\left(\beta_{3}+1\right)\left(\beta_{3}+\alpha_{1}+1\right)}\right] \\
& \mathrm{a}_{22}=-4 \mathrm{M}^{2}\left(\frac{\beta_{3}^{2} \mathrm{C}_{3}^{2}}{\left(2 \beta_{3}-1\right)\left(2 \beta_{1}+1\right)}+\frac{\beta_{1}^{2}}{2 \beta_{1}-1}\left\{1+\frac{2 \mathrm{C}_{3}}{\beta_{3}+1}+\frac{\mathrm{C}_{3}^{2}}{2 \beta_{3}+1}\right\}\right. \\
& \left.+\gamma t\left[\frac{2\left(\beta_{1}+\beta_{3}\right) \beta_{3}^{2} C_{3}^{2}}{\left(2 \beta_{3}-1\right)\left(2 \beta_{1}+1\right)}+\frac{2 \beta_{1}^{2}}{2 \beta_{1}-1}\left\{\beta_{1}+\frac{\left(2 \beta_{1}+\beta_{3}\right) C_{3}}{\beta_{3}+1}+\frac{\left(\beta_{1}+\beta_{3}\right) C_{3}^{2}}{2 \beta_{3}+1}\right\}\right]\right) \\
& \mathrm{a}_{23}=-4 \mathrm{M}^{2}\left(\frac{\beta_{3}^{2} \mathrm{C}_{3}^{2}}{\left(2 \beta_{3}-1\right)\left(\beta_{1}+\beta_{2}+1\right)}+\frac{\beta_{1} \beta_{2}}{\beta_{1}+\beta_{2}-1}\left\{1+\frac{2 \mathrm{C}_{3}}{\beta_{3}+1}+\frac{\mathrm{C}_{3}^{2}}{2 \beta_{3}+1}\right\}\right. \\
& +\gamma t\left[\frac{\left(\beta_{1}+\beta_{2}+2 \beta_{3}\right) \beta_{3}^{2} C_{3}^{2}}{\left(2 \beta_{3}-1\right)\left(\beta_{1}+\beta_{2}+1\right)}\right. \\
& \left.\left.+\frac{\beta_{1} \beta_{2}}{\beta_{1}+\beta_{2}-1}\left\{\left(\beta_{1}+\beta_{2}\right)+\frac{2\left(\beta_{1}+\beta_{2}+\beta_{3}\right) C_{3}}{\beta_{3}+1}+\frac{\left(\beta_{1}+\beta_{2}+2 \beta_{3}\right) C_{3}^{2}}{2 \beta_{3}+1}\right\}\right]\right)
\end{aligned}
$$




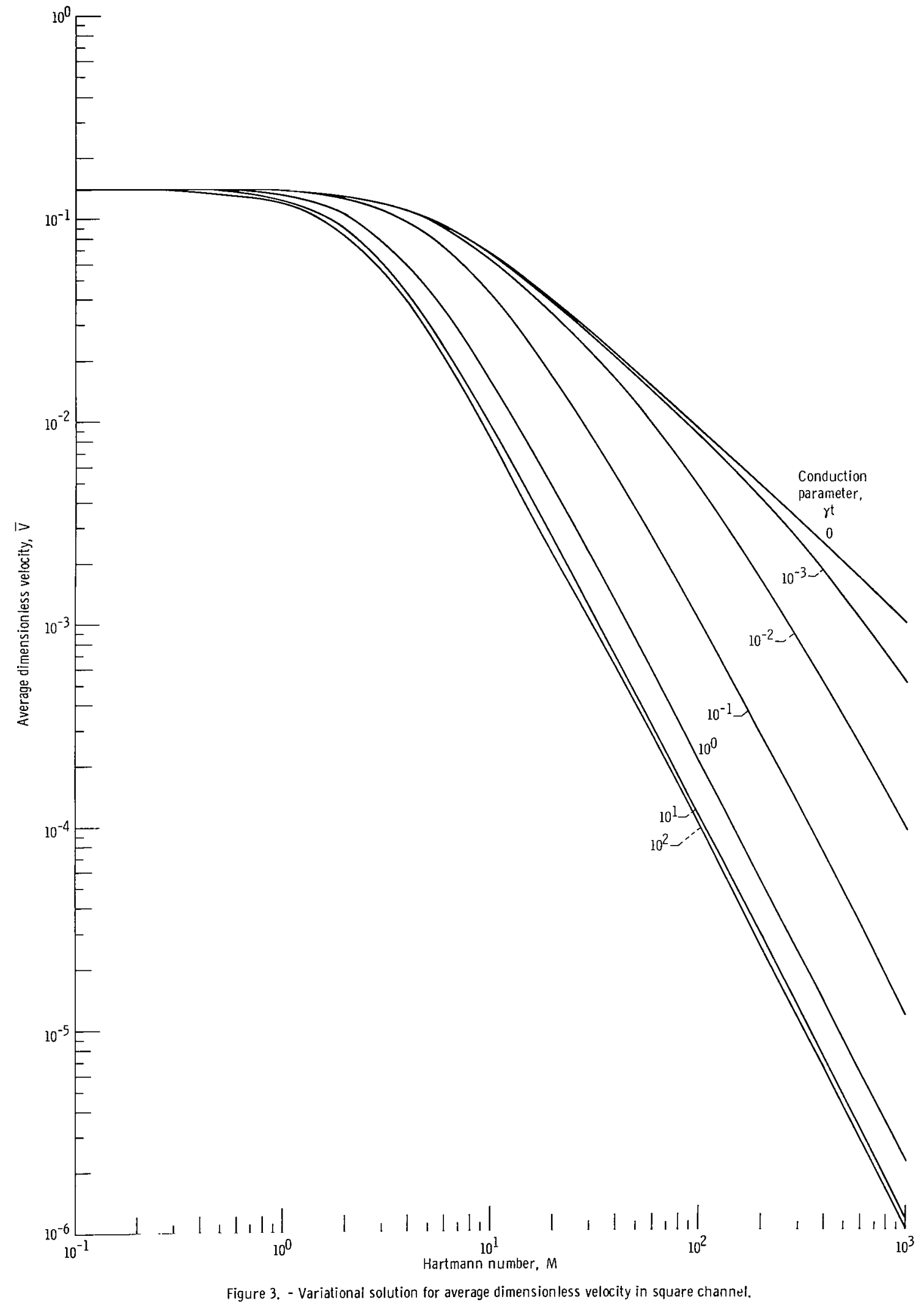




$$
\begin{gathered}
\mathrm{a}_{33}=-4 \mathrm{M}^{2}\left(\begin{array}{c}
\beta_{3}^{2} \mathrm{C}_{3}^{2} \\
\left(2 \beta_{3}-\frac{\beta_{2}^{2}}{1)\left(2 \beta_{2}+1\right)}+\frac{2 \mathrm{C}_{3}}{2 \beta_{2}-1}+\frac{\mathrm{C}_{3}^{2}}{2 \beta_{3}+1}\right\} \\
\beta_{3}+1
\end{array}\right\} \\
\left.+\gamma \mathrm{t}\left[\frac{2\left(\beta_{2}+\beta_{3}\right) \beta_{3}^{2} \mathrm{C}_{3}^{2}}{\left(2 \beta_{3}-1\right)\left(2 \beta_{2}+1\right)}+\frac{2 \beta_{2}^{2}}{2 \beta_{2}-1}\left\{\beta_{2}+\frac{\left(2 \beta_{2}+\beta_{3}\right) \mathrm{C}_{3}}{\beta_{3}+1}+\frac{\left(\beta_{2}+\beta_{3}\right) \mathrm{C}_{3}^{2}}{2 \beta_{3}+1}\right\}\right]\right) \\
\mathrm{d}_{1}=-\frac{8 \alpha_{1} \alpha_{2}}{\left(\alpha_{1}+1\right)\left(\alpha_{2}+1\right)}
\end{gathered}
$$

In obtaining equation (16), the "thin wall" approximation $\mathrm{t}<<1$ was made so that the results are directly comparable with published values. This approximation did not have to be made in order to use this formulation but was done since only thin wall results are available for comparison.

The maximum value for $F$ and the corresponding values for the parameters were found using a computer. Since the normalized cross-sectional area of the channel is 4 and $\mathrm{P}_{\mathrm{O}}=1$, the proportionality constant between the average dimensionless fluid velocity $\bar{V}$ and $F_{\text {st }}$ is $1 / 4$ (see eq. (14)). Values for $\bar{V}$ as a function of the Hartmann number $M$ are shown in figure 3 for various values of conduction parameter $\gamma$ t.

The results show that the average fluid velocity decreases as $M$ and $\gamma t$ increase. This decrease can be explained as follows: For $\mathbf{M} \neq 0$, an electric current is induced in the fluid due to the fluid motion. If $\gamma t=0$, the wall is an insulator and, hence, any induced current must form a closed path entirely in the fluid. Thus, the total electromagnetic force on the fluid is zero. However, since the electromagnetic force is not identically zero everywhere, the velocity profile of the fluid is distorted which, in turn, increases the viscous force and consequently reduces the average fluid velocity. For $\gamma \mathrm{t} \neq 0$, the induced current path is located partially in the wall so that there is a net electromagnetic force in addition to the viscous force acting to reduce the fluid velocity.

\section{Comparison of Results}

The variational solution can be compared with other solutions for some limiting cases. For $M=0$, the average dimensionless velocity from the variational solution is 0.1403 , independent of $\gamma t$, as compared with the exact value of 0.1406 , which can be computed using Fourier expansion techniques. 
The exact solution for the average flow in a rectangular channel with insulated walls $(\gamma t=0)$ and perfectly conducting walls $(\gamma t=\infty)$ has been obtained by Shercliff (ref. 3) and Chang and Lundgren (ref. 5), respectively. Each of these solutions is in the form of a series which converges poorly for large $M$. Williams (ref. 6), however, transformed these solutions and obtained asymptotic forms for the average velocity for large $M$. These solutions, simplified for $\mathrm{P}_{\mathrm{o}}=1$ and the square channel, are as follows:

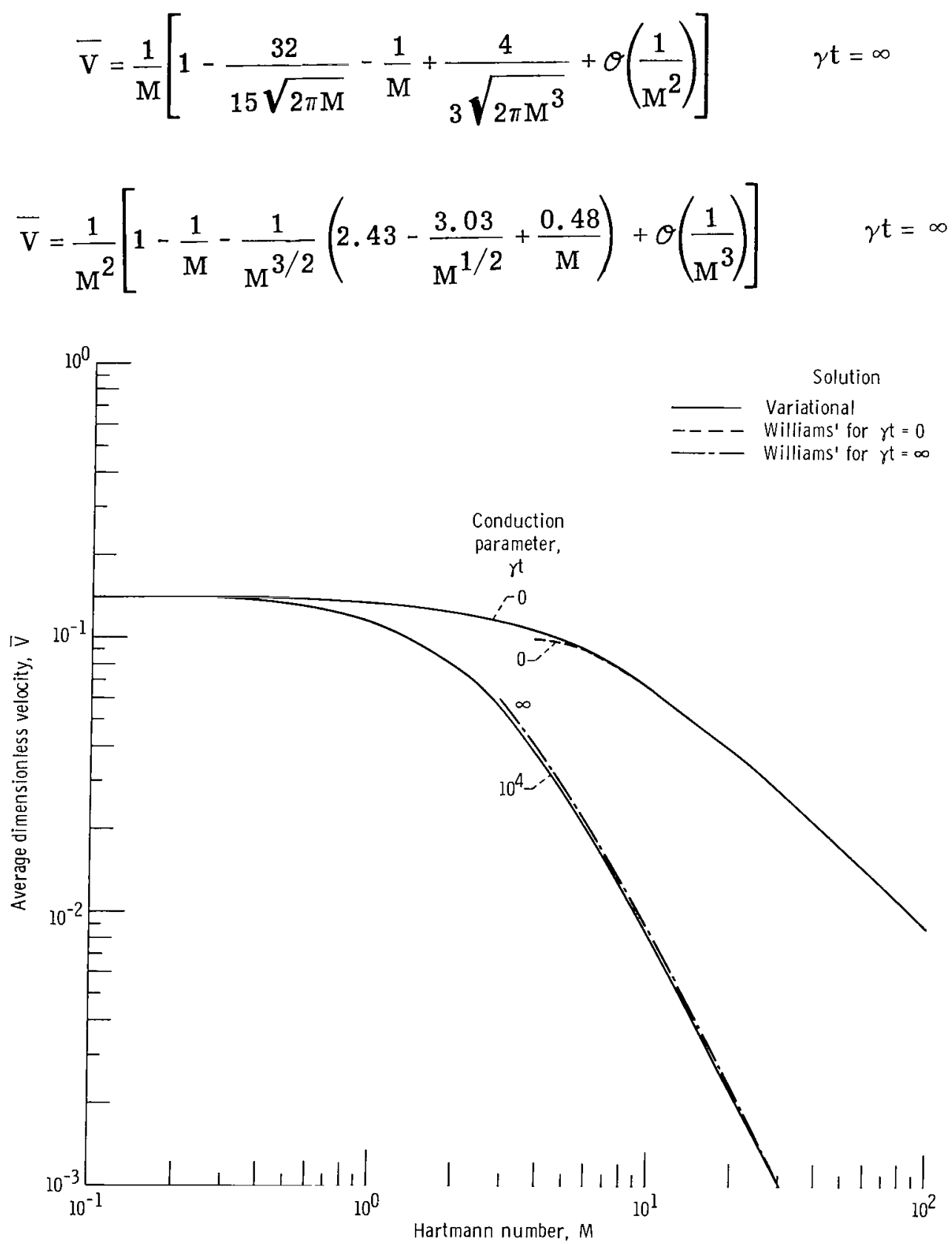

Figure 4. - Comparison of variational solution with Williams (ref. 6) asymptotic solutions for average dimensionless velocity. 
A comparison between the variational solutions and these asymptotic forms is shown in figure 4. The agreement between the two solutions for $\gamma t=0$ is excellent for $M \geq 10$. The variational solution for $\gamma t=10^{4}$ is always slightly less than the asymptotic form for $\gamma t=\infty$. The difference, however, decreases to less than 0.1 percent at $M=1000$.

A Fourier expansion type solution for the rectangular channel with thin walls of finite conductivity has recently been obtained by Chu (ref. 7). A comparison of his solution with the variational solution is shown in figure 5 . The agreement between these two solutions is also quite good. As shown, the variational solution for the average velocity is always slightly less than the series solution value. This is due to the fact that the computed maximum for $F$, and, hence, the average velocity, is always less than or equal to the true maximum for $F$ since the trial functions used are a subset of the entire class of admissible functions.

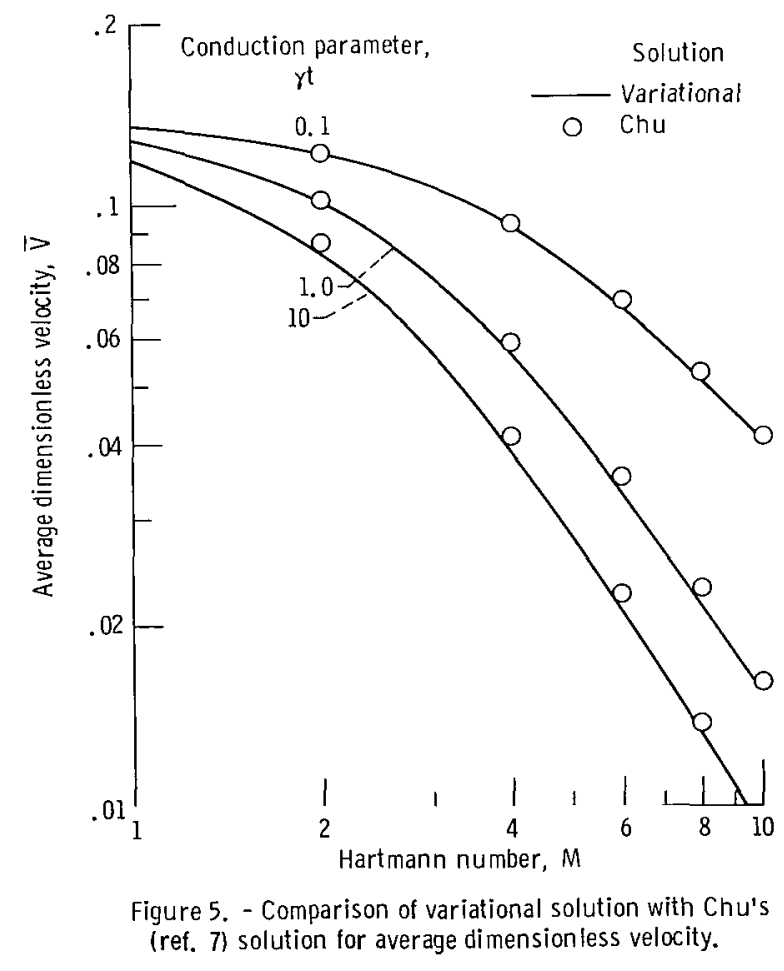




\section{CONCLUDING REMARKS}

A variational formulation was presented for a class of MHD channel flow problems. A stationary expression was developed that yielded solutions for the fluid velocity and the induced electric potential in a generalized channel. An example of a square channel with conducting walls was solved as an illustration. Very good agreement was obtained between the variational solution for the average velocity in the square channel and other published values.

Lewis Research Center,

National Aeronautics and Space Administration, Cleveland, Ohio, September 24, 1969, 120-27. 


\begin{tabular}{|c|c|c|c|}
\hline$[\mathrm{A}]$ & matrix (see eq. (16)) & $\hat{\mathrm{n}}$ & unit normal vector to con- \\
\hline $\mathrm{A}_{1}$ & adjustable parameter & & 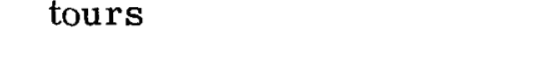 \\
\hline$a_{i j}$ & $i^{\text {th }}$ element of matrix $[A]$ & $\theta$ & order of \\
\hline$\hat{a}_{x}, \hat{a}_{y}$ & $\begin{array}{l}\text { unit vectors in } \mathrm{x} \text { - and } \\
\mathrm{y} \text {-directions }\end{array}$ & $\mathrm{P}_{\mathrm{J}_{\mathrm{a}}}$ & $\begin{array}{l}\text { power delivered to ex- } \\
\text { ternal load per unit } \\
\text { length of channel }\end{array}$ \\
\hline $\overrightarrow{\mathbf{B}}$ & magnetic flux density & $\mathbf{P}$ & dimensionless pressure \\
\hline $\mathrm{B}_{\mathbf{i}}$ & $\begin{array}{l}\text { induced magnetic flux } \\
\text { density }\end{array}$ & & gradient \\
\hline $\mathrm{B}_{\mathrm{o}}$ & $\begin{array}{l}\text { uniform applied magnetic } \\
\text { flux density }\end{array}$ & $\mathrm{P}_{\Delta \mathrm{p}}$ & $\begin{array}{l}\text { power supplied to fluid by } \\
\text { pressure gradient per } \\
\text { unit length of channel }\end{array}$ \\
\hline $\mathrm{C}_{\mathrm{fc}}, \mathrm{C}_{\mathrm{fi}}, \mathrm{C}_{\mathrm{co}}$ & $\begin{array}{l}\text { contours in generalized } \\
\text { channel cross section } \\
\text { (see fig. 1) }\end{array}$ & $\mathrm{P}_{\eta}$ & $\begin{array}{l}\text { power dissipated by vis- } \\
\text { cous force per unit length } \\
\text { of channel }\end{array}$ \\
\hline $\mathrm{C}_{1}, \mathrm{C}_{2}, \mathrm{C}_{3}$ & $\begin{array}{l}\text { adjustable parameters } \\
\text { matrix (see eq. (16)) }\end{array}$ & $\mathrm{P}_{\eta_{\mathrm{S}}}$ & $\begin{array}{l}\text { power dissipated by surface } \\
\text { viscous force per unit }\end{array}$ \\
\hline $\mathrm{d}_{1}$ & element of matrix $[\mathrm{D}]$ & & length of channel \\
\hline $\overrightarrow{\mathrm{E}}$ & electric field intensity & $\mathbf{P}_{\eta_{\mathrm{v}}}$ & $\begin{array}{l}\text { power dissipated by volume } \\
\text { viscous force per unit }\end{array}$ \\
\hline $\mathrm{F}$ & $\begin{array}{l}\text { stationary functional } \\
\text { (see eq. (8b)) }\end{array}$ & & length of channel \\
\hline$F_{\text {st }}$ & stationary value of $F$ & $P_{\sigma_{f}}$ & $\begin{array}{l}\text { power dissipated by ohmic } \\
\text { loss in fluid per unit }\end{array}$ \\
\hline $\mathrm{I}_{1}, \ldots, \mathrm{I}_{7}$ & $\begin{array}{l}\text { integrals (see eqs. } \\
\quad(7 \mathrm{a}) \text { to }(7 \mathrm{~g}))\end{array}$ & $\mathbf{P}_{\sigma}$ & $\begin{array}{l}\text { length of channel } \\
\text { power dissipated by ohmic }\end{array}$ \\
\hline $\overrightarrow{\mathrm{J}}$ & electric current density & & loss in walls per unit \\
\hline $\mathrm{J}_{\mathrm{a}}$ & $\begin{array}{l}\text { applied or generated elec- } \\
\text { tric current density }\end{array}$ & $\mathbf{p}$ & $\begin{array}{l}\text { length of channel } \\
\text { pressure }\end{array}$ \\
\hline $\mathrm{J}_{\mathrm{o}}$ & $\begin{array}{l}\text { dimensionless applied or } \\
\text { generated electric cur- } \\
\text { rent density }\end{array}$ & $\mathrm{S}_{\mathrm{f}}, \mathrm{S}_{\mathrm{c}}, \mathrm{S}_{\mathrm{i}}$ & $\begin{array}{l}\text { surfaces in generalized } \\
\text { channel cross section } \\
\text { (see fig. 1) }\end{array}$ \\
\hline $\mathrm{L}$ & $\begin{array}{l}\text { characteristic length of } \\
\text { channel }\end{array}$ & $\mathrm{t}$ & $\begin{array}{c}\text { dimensionless wall thick- } \\
\text { ness of square channel }\end{array}$ \\
\hline $\mathbf{M}$ & Hartmann number & & (see fig. 2) \\
\hline
\end{tabular}




\begin{tabular}{|c|c|c|c|}
\hline $\mathrm{U}$ & electric potential & $\eta$ & fluid viscosity \\
\hline V & $\begin{array}{l}\text { dimensionless fluid } \\
\text { velocity }\end{array}$ & $\lambda_{1}, \ldots, \lambda_{n}$ & $\begin{array}{l}\text { generalized adjustable } \\
\text { parameters }\end{array}$ \\
\hline$\vec{V}$ & $\begin{array}{l}\text { average dimensionless } \\
\text { fluid velocity }\end{array}$ & $\mu_{0}$ & $\begin{array}{l}\text { magnetic permeability of } \\
\text { free space }\end{array}$ \\
\hline $\overrightarrow{\mathrm{V}}$ & fluid velocity & $\rho$ & fluid density \\
\hline $\begin{array}{l}\mathrm{V}_{\mathrm{o}} \\
\mathrm{V}_{\mathrm{z}}\end{array}$ & $\begin{array}{l}\text { characteristic velocity } \\
z \text {-component of } \vec{V}\end{array}$ & $\sigma_{\mathrm{f}}, \sigma_{\mathrm{w}}$ & $\begin{array}{l}\text { fluid and conducting wall } \\
\text { electrical conductivities }\end{array}$ \\
\hline W & dimensionless potential & $\gamma$ & $\sigma_{\mathrm{w}} / \sigma_{\mathrm{f}}$ \\
\hline $\mathrm{X}, \mathrm{Y}, \mathrm{Z}$ & dimensionless coordinates & {$[\psi]$} & matrix (see eq. (16)) \\
\hline $\mathrm{x}, \mathrm{y}, \mathrm{z}$ & rectangular conordinates & & $\begin{array}{l}\text { evaluation of quantity on } \\
\text { fluid or wall side of }\end{array}$ \\
\hline$\alpha_{1}, \alpha_{2}$ & adjustable parameters & f $\quad 1$ & contour \\
\hline$\beta_{1}, \beta_{2}, \beta_{3}$ & adjustable parameters & Superscript: & \\
\hline$\delta$ & variational operator & $\mathrm{T}$ & transpose of matrix \\
\hline
\end{tabular}




\section{REFERENCES}

1. Tani, Itiro: Steady Flow of Conducting Fluids in Channels Under Transverse Magnetic Fields, With Consideration of Hall Effect. J. Aerospace Sci., vol. 29, no. 3, Mar. 1962, pp. 297-305.

2. Murgatroyd, W.: Experiments on Magneto-Hydrodynamic Channel Flow. Phil. Mag., vol. 44, no. 359, Dec. 1953, pp. 1348-1354.

3. Shercliff, J. A.: Steady Motion of Conducting Fluids in Pipes Under Transverse Magnetic Fields. Froc. Camb. Phil. Soc., vol. 49, pt. 1, Jan. 1953, pp. 136-144.

4. Hunt, J. C. R.: A Uniqueness Theorem for Magnetohydrodynamic Duct Flows. Proc. Camb. Phil. Soc., vol. 65, no. 1, Jan. 1969, pp. 319-327.

5. Chang, Chieh C.; and Lundgren, Thomas S.: Duct Flow in Magnetohydrodynamics. Zeit. f. Angew. Math. Mech., vol. 12, 1961, pp. 100-114.

6. Williams, W. E.: Magnetohydrodynamic Flow in a Rectangular Tube at High Hartmann Number. J. Fluid Mech., vol. 16, pt. 2, June 1963, pp. 262-268.

7. Chu, W. H.: On MHD Flow in a Rectangular Duct of Arbitrary Conductivity for Arbitrary Hartman Number. Southwest Research Inst., Oct. 30, 1968. 


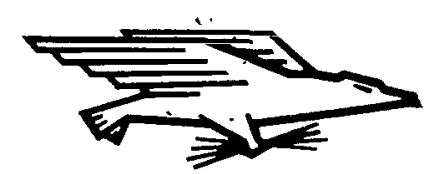

POSTAGE AND FEES PAID NATIONAL AERONAUTICS AND SPACE ADMINISTRATION

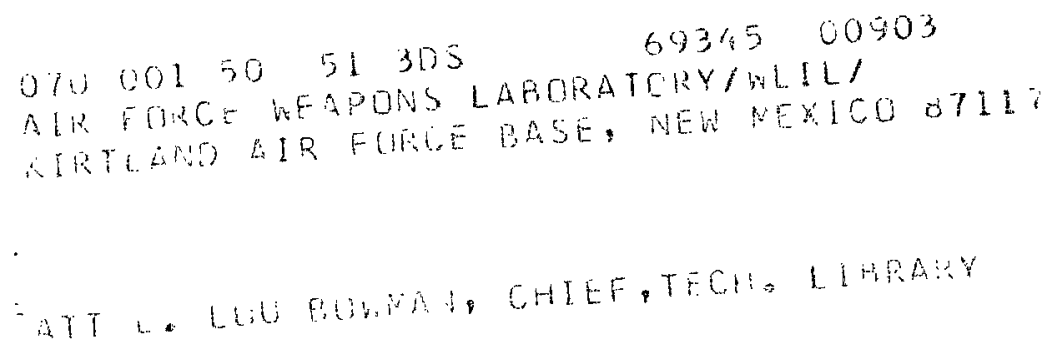

POSTMASTER :
If Undeliverable (Section 158 Postal Manual) Do Not Return

"The aeronatitical and space activities of the United. States shall be conducted so as to contribute. . . to the expansion of buman knowledge of pbenomena in the atmospbere and space. The Administration shall protide for the widest practicable and appropriate dissemination of information concerning its actinities and the results thereof."

- National. Aeronautics and Space Act of 1958

\section{NASA SCIENTIFIC AND TECHNICAL PUBLICATIONS}

TECHNICAL REPORTS: Scientific and technical information considered important, complete, and a lasting contribution to existing knowledge.

TECHNICAL NOTES: Information less broad in scope but nevertheless of importance as a contribution to existing knowledge.

TECHNICAL MEMORANDUMS:

Information receiving limited distribution because of preliminary data, security classification, or other reasons.

CONTRACTOR REPORTS: Scientific and technical information generated under a NASA contract or grant and considered an important contribution to existing knowledge.
TECHNICAL TRANSLATIONS: Information published in a foreign language considered to merit NASA distribution in English.

SPECIAL PUBLICATIONS: Information derived from or of value to NASA activities. Publications include conference proceedings, monographs, data compilations, handbooks, sourcebooks, and special bibliographies.

TECHNOLOGY UTILIZATION PUBLICATIONS: Information on technology used by NASA that may be of particular interest in commercial and other non-acrospace applications. Publications include Tech Briefs, Technology Utilization Reports and Notes, and Technology Surveys.

Details on the availability of these publications may be obtained from:

\section{SCIENTIFIC AND TECHNICAL INFORMATION DIVISION NATIONAL AERONAUTICS AND SPACE ADMINISTRATION Washington, D.C. 20546}

